\title{
Describing the Molecular Mechanism of Organic Reactions by Using Topological Analysis of Electronic Localization Function
}

\author{
J. Andrés ${ }^{1}$, S. Berski ${ }^{2}$, L. R. Domingo ${ }^{3}$, V. Polo ${ }^{4}$ and B. Silvi ${ }^{5}$ \\ ${ }^{1}$ Departamento de Química Física y Analítica, Universitat Jaume I, 12071, Castelló. Spain \\ ${ }^{2}$ Faculty of Chemistry, University of Wroclaw, F. Joliot-Curie 14, 50-383 Wroclaw, Poland \\ ${ }^{3}$ Departamento de Química Orgánica, Universidad de Valencia, Dr. Moliner 50, 46100 Burjassot, Valencia, Spain \\ ${ }^{4}$ Departamento de Química Orgánica y Química Física. Universidad de Zaragoza, Pedro Cerbuna 12, 50009-Zaragoza, Spain \\ ${ }^{5}$ Laboratoire de Chimie Theórique, Université Pierre et Marie Curie, 4 Place Jussieu, 75252 Paris Cedex, France
}

\begin{abstract}
Here, we provide an essay on the analysis of the reaction mechanism at the molecular level; in particular, the evolution of the electron pair, as it is provided by the ELF, is used to decribe the reaction pathway. Then, the reaction mechanism is determined by the topological changes of the ELF gradient field along a series of structural stability domains. From this analysis, concepts such as bond breaking/forming processes, formation/annihilation of lone pairs and other electron pair rearrangements arise naturally along the reaction progress simply in terms of the different ways of pairing up the electrons. To visualize these results some organic reaction mechanisms (the thermal ring aperture of cyclobutene and cyclohexa-1,3-diene) have been selected, indicating both the generality and utility of this type of analysis.
\end{abstract}

Keywords: ?????????????????????????????????????

\section{INTRODUCTION}

Understanding chemistry without the concept of chemical bonding (structure) and how these chemical bonds are forming/breaking (reactivity) along a given chemical reactions is close to impossible. When atoms in a molecule change their specific arrangement, a formal chemical rearrangement takes place. Then, a chemical reaction involves breaking of bonds between atoms and the formation of new ones and the time scale of chemistry is therefore the time scale for the motion of atoms, and this endeavour is essence of the chemical reactivity, permeating the whole of chemistry $[1,2]$. However, the fundamental details of these rearrangements are still a subject under discussion and have not been understood satisfactorily and many questions remain unanswered.

A physical chemist or physical organic chemist needs to understand the detailed sequence of bond making/forming processes by which known and new reactions take place, i.e. the reaction mechanism. Therefore, the concept of reaction mechanism plays a major role in chemistry and represents a synthesis of our understanding of the way in which the topological changes in the bonding structure of a reactant or product are correlated as the reaction proceeds. At the macroscopic level of description, the reaction mechanism consists of the specification of the participating species (reactants, products, and/or possible intermediates) and catalysts and the connectivity of these species due to chemical reactions [3]. This connectivity can be expressed by a series of elementary reactions, the sum of which yields the reaction mechanism.

Obtaining a plausible reaction mechanism consists in three well defined stages: (i) identifying individual chemical species, either by physical or by chemical means, (ii) isolating the species contribu-

*Address correspondence to this author at the Departamento de Química Física y Analítica, Universitat Jaume I, 12071, Castelló. Spain; Tel: -------------; Fax: -------------; E-mail: ting to one elementary reaction step in the system, (iii) determining the stoichiometry of that step, and (iv) determining the kinetics of that step.

Generally speaking, a chemical reaction can be associated with transformation of energy and the one dimensional energy diagram illustrating the progress of a reaction $\mathrm{R} \rightarrow \mathrm{P}$ is depicted schematically in Fig. (1). The activation energy $E^{\#}$ to be surmounted is usually provided by thermal energy kT, with k being Boltzmann's constant and $\mathrm{T}$ the temperature.

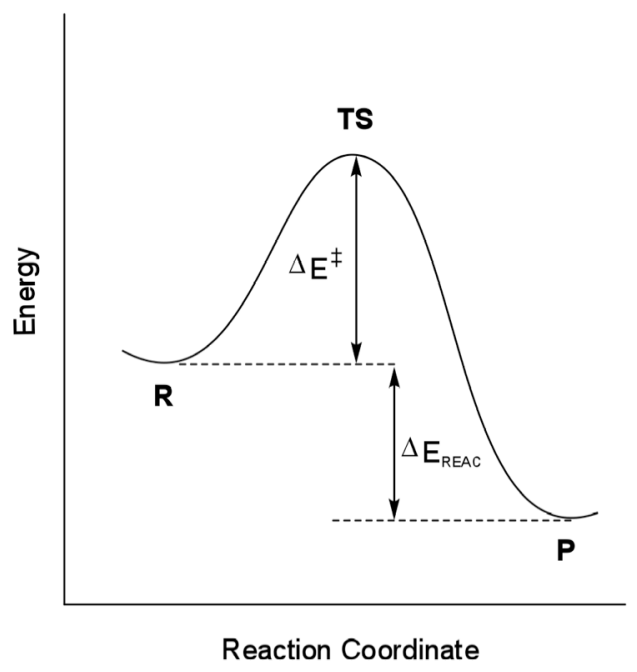

Fig. (1). A standard representation of the energy profile for a given unimolecular chemical rearragement $\mathrm{R}->\mathrm{P}$ via $\mathrm{TS}$.

This diagram corresponds to an elementary chemical step from reactants $(\mathrm{R})$ to product $(\mathrm{P})$, via the corresponding transition state (TS). Solving this problem requires (a) determining the free-energy profile, (b) observing the TS experimentally or theoretically, and (c) 
finding TS models that match the experimental data. However, one step further is the nature of the corresponding reaction mechanism at microscopic level.

The study of the different stages at the atomic level of the chemical rearrangements as well as how initial constituents (ions/atoms/molecules) reach bonding patterns are essential for understanding the atomic-scale physics/chemistry that determine many properties, but it has long been regarded as a difficult problem. This knowledge is at the heart of a deeper understanding of the chemical reactivity and to this end is necessary to known: i) how and where the bond marking/forming processes associated to the rearrangement from reactants to corresponding products take place, ii) TS, the family of configurations through which reactants evolve into products, is the key to molecular level understanding of chemical reactivity [4].

From the point of view of fundamental theory, elementary chemical reactions are simply the detailed dynamics of the electrons and atomic nuclei that constitute the total molecular system of reacting species. The current electronic structure theory of molecules, i.e. quantum chemistry, can provide the accurate snapshots of electronic distribution associated with geometrical changes of even very large molecules. In the deeper study of chemical reactivity, we sometimes want to identify how electronic flow in a molecule occurs as a function of chemical reaction progress. During a chemical rearrangement, the motion of the atoms can be accompanied by a reorganization of the electronic structure, and recent experimental progress allows for probing this change [5] in real time. However, it is the motion of the nuclei that sets the time scale because the electronic reorganization exactly tracks the shifts in the positions of the nuclei. As the heavier nuclei move, the light electrons immediately adapt. Dynamical motion of atoms within molecules and solids can be captured with pump probe techniques using ultrashort laser pulses [6-8] as witnessed by observations of the evolution of a chemical reaction [9] or the melting of a solid in situ [10]. The exploration of even faster processes, such as electron motion inside an atom, has now become possible with the generation of attosecond (as $=10^{-18} \mathrm{~s}$ ) extreme ultraviolet pulses [11-13].

The dynamics of electrons and atomic nuclei takes place primarily via their mutual Coulombic forces and is governed by the time dependent Schrodinger equation. The theory and methodologies for solving this equation for general systems of electrons and nuclei have undergone dramatic improvements in recent years. Both the increased power of electronic computers and the introduction of more efficient yet conceptually simpler and more accurate theoretical descriptions are responsible for this development. The dispar masses of even the lightest nucleus and an electron have led to the widely accepted view that an adequate description of thermal (very low energy) processes can be achieved assuming an effective separation of electronic and nuclear degrees of freedom, i.e. the BornOppenheimer (BO) approximation. The physical picture for this approximation is that the electrons instantly adjust to the current position of the nuclei so that the equilibrium arrangement of the bonded atoms is determined as a minimum of the electronic energy. In the BO approximation, the system is confined to be in a single stationary electronic state, and if this confinement is strict then there is no electronic time scale that is relevant to chemistry. Considering that the electron dynamics to take place in the field of stationary nuclei introduces the concept of an electronic Hamiltonian with its pointwise determined stationary electronic states and associated to the paradigm of the potential energy surface (PES) [14]. The BO or adiabatic approximation is widely used to simplify the very complex many-body problem of electrons in molecules, assuming that electrons equilibrate much faster than the atomic motion of the ionic cores. This approximation can be considered as static representation of the corresponding chemical reactions and without this approximation, most molecular problems become difficult or impossible to solve analytically. Considering the BO approximation, the reactive systems move from the reactant minimum of the PES through TSs and intermediates to the product minimum.

The determination of the ground-state and excited-state PESs and associated stationary electronic states for a molecular system require the choice of a set of internal coordinates for the nuclei, a far from trivial problem, and accurate interpolation procedures to estimate energies at intermediate geometries. Each PES exhibits considerable structure for a polynuclear molecular system and often provides attractive pictures with local minima corresponding to stable species and transition states serving as gateways for the system to move between such minima, commonly along minimumenergy paths. Molecular structures (reactants, products, and possible intermediates) are associated with the minimum positions in the valleys, while the TS is a saddle point of index one on the PES. In the analysis of PESs, molecular processes are described by means of reaction paths, which are continuous curves on the PES connecting two minima through a saddle point (first-order maximum) and usually associated with steepest-descent curves [15]. The energetic aspects of the reaction can be obtained from the energies of these stationary points, that is, the thermodynamic and kinetic parameters can be derived from the relative values of energy between them. Therefore, the standard description of chemical reactivity tends to rely on calculation of the geometries and energies of these stationary points lying on the reaction pathway of a given chemical rearrangement. The theoretical construct of a PES is central to accepted pictures of chemical structure and bonding.

Theoretical and computational chemistry (TCC) has witnessed a great deal of research to study the energetics of chemical reactions [16] and has found its way into the everyday work of many experimental chemists. Recent advances in the methods and techniques of TCC have made it possible to develop a more complete theoretical understanding of the elementary molecular steps, along with reasonably accurate prediction of reaction energies in both gas phase and condensed media, including homogeneous, heterogeneous and enzyme catalysis [17]. Calculations can predict the outcome of chemical reactions, afford insight into reaction mechanisms, and be used to interpret structure, bonding and energies in molecules. Thus, contemporary theory offers tremendous opportunities in experimental chemical research. The prediction, from first principles, of the structure and energy of molecules taking place along this energy profile associated to chemical reactions, constitutes a major activity of TCC. Such an endeavor has not been an easy one though, involving several research areas which have provided solid basis for theories and models that have pervaded over the years in ongoing research efforts [16]. Within the broad scope of these investigations, particular interest has been focused on extracting information about the stationary points of the PES. Despite the fact that minima, maxima, and saddle points are useful mathematical features of the energy surface to reaction-path following [18], it has been difficult to attribute too much chemical or physical meaning to these critical points [19]. Whereas the reaction rate and the reaction barrier are chemical concepts, which have been rigorously defined and experimentally studied since the early days of the transition state theory [20], the structure of the TS remains as a quest of physical organic chemistry. Understanding the TS is a fundamental 
goal of chemical reactivity theories, which implies the knowledge of the chemical events that take place to better understand the kinetics and the dynamics of a reaction. On the other hand, a variety of density descriptors have been employed to study chemical reactions [21-23]. Among them, it is worthy to mention the reaction force studies on the PES, which have been employed to characterize changes in the structural and/or electronic properties in chemical reactions [24-28]. However, a step further is to describe the reaction mechanism of elementary reactions in a simple and direct fashion.

From a quantum mechanical perspective, the interpretation of chemical data is directly related to the extraction of the information contained in the wave function of molecular systems that can be represnted by density matrices, one-particle density matrix is the electron density, $\rho(r)$. Then, all atomic and molecular properties of a chemical system are governed by the $\rho(r)$ distribution. Since chemical reactions are essentially movement of pairs of electrons and such reactions proceed by $\rho(r)$ redistributions, the methods that deal with the analysis of the $\rho(r)$ distribution should have a particular appeal for chemists and help to understand the electron structure of molecules and thus chemical reactivity. Important information about the charge distribution and about its changes along a given chemical rearrangement intermolecular interactions can be obtained by means of population analysis, where the total number of electrons is divided to individual atoms or even to atomic orbitals. The most popular are the population analysis introduced by Mulliken [29] and Löwdin [30]. Still increasing weight is also attached to the natural bond orbital (NBO) method proposed by Weinhold et al [31]. All these methods try to represent the molecule as a distribution of point charges and the their subsequent analysis yields characteristic points that reflect the use of atom-centered basis sets. This disadvantage of traditional methods of the electron density distribution is remedied using a topological technique known as AIM (atoms-in-molecules) of Bader to focus on the local bonding [32]. A great interest and widespread use of this method is due to the fact that, as opposed to the wave function quantum mechanics, the AIM method gives the opportunity to have an insight into a region of a system. This opportunity meets the interest of most chemists who wish to have a theoretical tool to study a small part of a molecule only, instead of dealing with the total energy of a whole system.

The AIM technique in essence classifies the curvature in the molecular electron density into four different types, of which the most pertinent in the present context is named a bond-critical point. Despite the name, its interpretation as meaning a 'chemical bond' remains controversial [33]. Alternatively, a chemical reaction can be studied from the redistribution of the electron density along the reaction path connecting the stationary points. It is possible to understand the bond breaking/forming processes in a reaction. Bader and co-workers pioneered the study of the structural change based in the electron density using the Thom's theory of elementary catastrophes [32]. Another representation of the electronic wavefunction is the electron localization function or 'ELF' $[34,35]$.

It is thought that the bifurcation thresholds in the ELF function for the formation of so-called disynaptic basins may illuminate the deepest nature of bonds. Silvi and co-workers developed the bonding evolution theory as a generalization of the Bader's work to other scalar fields as ELF $[36,37]$. Several research groups have used the electron density [38-42], its laplacian [43], ELF [44-48], and electrostatic potential [49] to study reaction mechanisms or conformational changes of several systems using these approaches.
In this paper, we discuss various aspects of chemical reactivity that have been addressed in two well known chemical rearrangements: the thermal ring aperture of cyclobutene 1 and cyclohexa1,3-diene 3 to yield buta-1,3-diene 2 and (Z)-hexa,1,3,5-trien 4, respectively, (see Scheme).

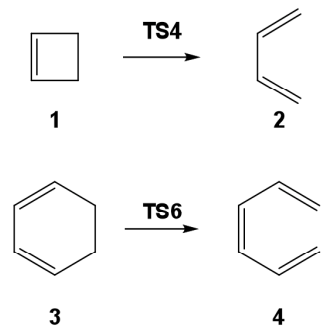

Scheme.

The delineation of factors that control the pair electron reorganization on these rearrangements is complicated. In addition to the inherent electronic properties, their reactivity depends on the accessible conformational space and other factors. This underscores the difficulties in understanding the balance between steric and electronic factors that govern the outcome of organic transformations. We have focused on the proposed reaction mechanisms in an attempt to highlight the key concepts that are emerging on the basis of these studies.

\section{TOPOLOGICAL ANALYSIS OF ELF AND CATAS- TROPHE THEORY}

ELF provides a connection between the wave function and the chemical structure. This is a scalar field that is different than the used by the AIM approach, since it is based in the first-order density matrix and is defined such that its values range between 0 and 1 [34]. Topological analysis of ELF [50] presents a mathematical model of the Lewis's valence theory $[51,52]$ and provides a partition of the molecular space into basins of attractors that are in a one-to-one correspondence with expected chemical properties. Originally, ELF was designed by Becke and Edgecombe [34] in order to provide an orbital independent description of the electron localization. Their expression for the ELF is

$$
\eta(\mathbf{r})=\frac{1}{1+\left(\frac{D_{\sigma}}{D_{\sigma}^{0}}\right)^{2}}
$$

where $D_{\sigma}$ and $D_{\sigma}^{0}$ represent the curvature of the electron pair density of the same spin $\sigma$ for a real system (the Fermi hole curvature) and the homogeneous electron gas of the same density, respectively. By definition, the ELF values are confined between 0 and 1 . The original derivation was based on the Laplacian of conditional Hartree-Fock probability of finding a $\sigma$-spin electron at $\mathbf{r}_{2}$ when another $\sigma$-spin electron is located at $\mathbf{r}_{1}$, namely:

$$
D_{\sigma}=\left(\nabla_{2}^{2} P_{\text {cond }}^{\sigma \sigma}(1,2)\right)_{1=2}=\sum_{i=1}^{i=N}\left|\nabla \varphi_{i}\right|^{2}-\frac{1}{4} \frac{\left|\nabla \rho^{\sigma}(1)\right|^{2}}{\rho^{\sigma}(1)}
$$

expressed in terms of orbital contributions. $D_{\sigma}^{0}(\mathbf{r})$ is the ThomasFermi kinetic energy for the homogeneous electron gas of the same density:

where $\mathrm{C}_{\mathrm{F}}$ is the Fermi constant.

$$
D_{\sigma}^{0}(\mathbf{r})=C_{F} \rho(\mathbf{r})^{\frac{5}{3}}
$$


The characterization of electron pair rearrangements for describing the changes in the bonding scheme along the reaction pathway can be considered as the most desirable way to analyze a reaction mechanism. However, this description only can be obtained through a quantitative assessment of electronic pairing rather than intuitive or qualitative descriptions. In order to fulfill these requirements, the bonding evolution theory (BET), consisting of the joint use of ELF and the catastrophe theory (CT) of Rene Thom [53] was proposed by Krokidis et al [37] as a new tool for the contemporary understanding of electronic rearrangements in chemical processes.

The dynamical system theory is based on the analogy between a vector field of class $\mathrm{C}^{1}$ bound on a manifold and a velocity field, i.e. in the present case:

$$
\nabla \eta(\mathbf{r})=\frac{d \mathbf{r}}{d t}
$$

Integrating $\mathrm{dr} / \mathrm{dt}$ with respect to the fictitious time variable $t$ determines trajectories which start and end in the neighbourhood of points at which the gradient vanishes, the $\alpha$ and $\omega$ limits, respectively. Of particular importance are the critical points $P$ of coordinate $\mathrm{r}_{P}$ at which $\nabla \eta\left(\mathrm{r}_{P}\right)=0.0$ and which are characterized by their index $I_{P}$, i.e. the number of positive eigenvalues of the second derivative (hessian) matrix. A critical point is said hyperbolic when all the eigenvalues of the hessian matrix differ from zero. The set of points by which are built trajectories having a given critical point $P$ as $\omega$ limit is called the stable manifold of $P$. It is therefore possible to achieve the partition of the geometrical space occupied by a molecule into basins of attractors, in other words into stable manifolds of critical points of index 0 .

The topological partition of the ELF gradient field yields basins of attractors which can be identified as corresponding to atomic cores, bonds and lone pairs. In a molecule one can find two types of basins: i) core basins surrounding nuclei with atomic number $\mathrm{Z}>2$ and labeled $\mathrm{C}(\mathrm{A})$ where $\mathrm{A}$ is the atomic symbol of the element. ii) valence basins that are characterized by the number of atomic valence shells to which they participate, or in other words by the number of core basins with which they share a boundary. This number is called the synaptic order [44]. Thus, there are monosynaptic, disynaptic, trisynaptic basins and so on. Monosynaptic basins, labeled V(A), correspond to the lone pairs of the Lewis type or non-bonding regions. A basin is disynaptic if it connects the core of two nuclei $\mathrm{A}$ and $\mathrm{X}$ and, thus, corresponds to a bonding region between $A$ and $X$ and labeled $V(A, X)$. The valence shell of a molecule is the union of its valence basins. The valence shell of an atom, say $\mathrm{A}$, in a molecule is the union of the valence basins whose label lists contain the element symbol A. This description recovers Lewis's picture of the bonding and provide very suggestive graphical representations of molecular systems. A quantitative analysis is further achieved by integrating the electron density and the pair functions over the volume of the basins yielding both basin populations and the corresponding covariance matrix [55] which measures the electron and support a phenomenological interpretation in terms of weighted mesomeric structures.

The ELF depends upon a set of parameters such as the nuclear coordinates, the electronic state, the interaction with an external field [56], referred as the control space. The topology depends therefore obviously of the value of the control space parameters. The changes are ruled by the Poincaré-Hopf theorem which state that:

$$
\sum_{P}(-1)^{I_{P}}=1
$$

introducing a very strong constraint due to the structure of the geometrical space.

In our case the corresponding reaction mechanism is analyzed along the energy profile connecting the stationary points on PES by means of the intrinsic reaction coordinate (IRC) of Fukui $[15,18]$ as the reaction pathway which links the chemical structures and therefore the topologies of the ELF gradient fields of the reactants with those of the product. Along this pathway, the system experiences a series of structural stability domains (SSDs) within all the critical points are hyperbolic and separated by catastrophe or turning points (TPs) where at least one critical point is non hyperbolic. The bifurcation catastrophes occurring at these TPs are identified according to Thom's classification [57] which gives access to their unfolding, a compact polynomial expression which contains all the information about how ELF may change as the control parameters change. In this way, a chemical reaction is viewed as a sequence of SSDs connecting by TPs which can be identified to chemical events such as bond forming/breaking processes, creation/annihilation of lone pairs and other types of electron pair rearrangements.

Only three elementary catastrophes have been recognized so far in the studied chemical reactions: the fold, cusp and elliptic umbilic catastrophe. The fold catastrophe transforms a wandering point (i.e. a point which is not a critical one) into two critical points of different parity. Its unfolding is $x^{3}+u x, x$ is the direction of the eigenvector corresponding to the eigenvalue of the Hessian matrix which changes of sign and $u$ is the control space parameters which governs the discontinuity. The cusp catastrophe transforms a critical point of a given parity into two critical points of the same parity and one of the opposite parity. Finally, the elliptic umbilic catastrophe changes the index of one critical point by 2 .

BET [37] has been applied to different elementary reactions as proton transfers $[36,58]$, isomerisations [59], electron transfers [60] and studies on two-state reactivity [61-63]. A systematic investigation of the mechanism of important organic reactions such as the Diels-Alder reactions [45,46] the 1,3-dipolar reaction between fulminic acid and acetylene [44], the molecular mechanism of the Bergman cyclization [64], the trimerization of acetylene [65] the "chameleonic vs centauric" mechanisms of the Cope rearrangement of 1,5 hexadiene and its cyano derivatives [66] the Nazarov cyclization [67] and the $\mathrm{S}_{\mathrm{N}} 2$ reaction [68].

\section{COMPUTATIONAL DETAILS}

DFT calculations have been carried out using the B3LYP $[69,70]$ exchange-correlation functional, together with the standard 6-31G(d) basis set [71]. The optimizations were carried out using the Berny analytical gradient optimization method [72]. The stationary points were characterized by frequency calculations. The IRC paths were traced by using the second order González-Schlegel integration method $[73,74]$. All calculations were carried out with the Gaussian 03 suite of programs [75].

The reaction path (B3LYP/6-31G(d)) has been followed using the IRC procedure $[15,18]$ in mass-weighted internals. The step of 0.1 [amu $^{1 / 2}$ bohr] along the path has been assumed. The ELF function has been calculated over a rectangular parallelepipedic grid with step of 0.045 bohr.

A chemical equation in quantum chemical topology [76,77] consists of the chemical formulas (or systematic names), a plus sign and "sequence of catastrophes" (SC) [36], which replaces a symbol of arrow " $\rightarrow$ ". The "sequence of catastrophes" encompasses changes that strictly involve the forming/breaking of chemical bonds 


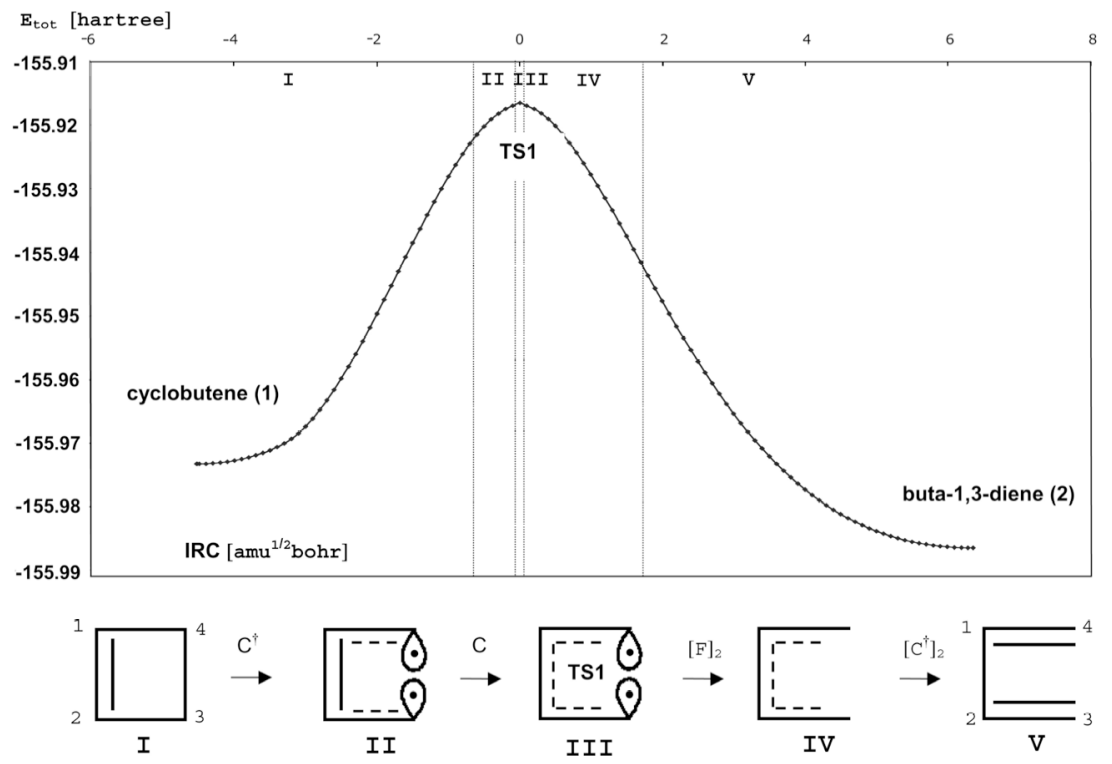

Fig. (2). Energy profiles for the thermal ring aperture of cyclobutene (1) calculated by means of the IRC method, with a step size of 0.1[amu1/2bohr]. Below the graph a schematic representation of the reaction mechanism for each figure is depicted from the perspective of the ELF analysis (full lines and ellipses representing disynaptic and monosynaptic basins, respectively, dotted lines indicates a large basin population), the type of turning point is noted as in the text.

and lone pairs. It is expressed by means of a formula: $\mathrm{N}_{1}-\mathrm{N}_{2-}$ FCSHEBP ...- $\mathrm{N}_{3} . \mathrm{N}_{1}$ is the ordinal number of an analyzed sequence and it can be omitted when only one reaction is considered $\left(\mathrm{N}_{1}=1\right)$; $\mathrm{N}_{2}$ is the number of observed steps (domains of structural stability) which is by one larger than the number of catastrophes shown in SC, "FCSHEBP" are symbols of catastrophes taken from first letters of their original names proposed by Rene Thom $[53,57]$ i.e. $F-$ the fold, $C$ - the cusp, $S$ - the swallow tail, $H$ - the hyperbolic umbilic, $E$ - the eliptic umbilic, $B$ - butterfly, $P$ - parabolic umbilic; $\mathrm{N}_{3}$ means the end of the sequence i.e. $\mathrm{N}_{3}=0$. For processes where some bifurcations occur simultaneously, catastrophes are denoted by $[A A]$ or $[A]_{\mathrm{N} 4}$ where $\mathrm{N}_{4}$ stands for the number of catastrophes. Moreover, bold symbols are used to emphasize the first bond formation whereas the ${ }^{\dagger}$ superscript is used for those catastrophes which increase either the number of basins or the synaptic order, for example $\mathrm{C}^{\dagger}$ corresponds to a cusp catastrophe in which an attractor gives rise to two new attractors and a saddle point of index 1 . In this way, a chemical reaction can be decomposed in a well defined sequence of electron pair topologies which can be identified with chemical concepts commonly used.

Using the "sequence of catastrophes" the reaction between ethene and 1,3-butadiene studied previously [46] is represented as $\mathrm{C}_{4} \mathrm{H}_{6}+\mathrm{C}_{2} \mathrm{H}_{4}: 1-7-[C]_{2} C\left[F^{\dagger}\right]_{2}\left[F^{\dagger}\right]_{2}[C]_{2} C^{\dagger}-0: \mathrm{C}_{6} \mathrm{H}_{10}$. It consists of 7 steps, 10 catastrophes (4 occurring simultaneously). New chemical bonds (two $\mathrm{C}-\mathrm{C}$ bonds) are formed by two cusp catastrophes $\left([\mathrm{C}]_{2}\right)$, which decrease the number of basins (a lack of the " $f$ "symbol) in the fifth step.

At Figs. (2 and 3) (Lewis-like formulas) the C-C bonds in 1 and 3 are represented as $\mathrm{C}_{\mathrm{i}}=\mathrm{C}_{\mathrm{j}}$ double bonds when two attractors/basins $\mathrm{V}_{\mathrm{i}=1,2}\left(\mathrm{C}_{\mathrm{i}}, \mathrm{C}_{\mathrm{j}}\right)$ are observed, and as $\mathrm{C}_{\mathrm{i}}-\mathrm{C}_{\mathrm{j}}$ single bonds when only single attractor/basin $\mathrm{V}\left(\mathrm{C}_{\mathrm{i}}, \mathrm{C}_{\mathrm{j}}\right)$ is found. However, localization of such two attractors is not a straightforward proof of the double bond. The non-bonding monosynaptic basin $\mathrm{V}\left(\mathrm{C}_{\mathrm{i}}\right)$ is represented by the elipse with point inside.

An analysis of the openning of 1 revealed some problems with determination of the catastrophe positions on the IRC path (between steps: II, III and III, IV), which were associated with a characterisation of the $\mathrm{C} 1-\mathrm{C} 2, \mathrm{C} 1-\mathrm{C} 4, \mathrm{C} 2-\mathrm{C} 3$ bonds by pairs of the attrac- tors/basins $\mathrm{V}_{\mathrm{i}=1,2}\left(\mathrm{C}_{\mathrm{i}}, \mathrm{C}_{\mathrm{j}}\right)$ or single attractor/basin $\mathrm{V}\left(\mathrm{C}_{\mathrm{i}}, \mathrm{C}_{\mathrm{j}}\right) \quad(\mathrm{i}=1,2 ; \mathrm{j}=$ $2,3,4)$. Such problem has not been observed for catastrohes occurring between I, II and IV, V steps. In our opinon it may be originated by the diradical character of the opening mechanism of 1cyclobutene and it should be studied using multireference method in the future. An analysis carried out for 3 has not indicated any problems with identifications of catastrophe positions.

\section{RESULTS AND DISCUSSION}

The thermal opening of cyclobutene 1 and cyclohexa-1,3-diene 3 have one-step mechanisms with high activation energies: 35.6 (TS1) and 45.0 (TS2) kcal/mol; while formation of buta-1,3-diene 2 is exothermic by $-12 \mathrm{kcal} / \mathrm{mol}$, formation of (Z)-hexa,1,3,5-trien 4 is endothermic by $25 \mathrm{kcal} / \mathrm{mol}$. The interatomic distances $\mathrm{r}(\mathrm{C} 3 \cdots \mathrm{C} 4)$ and $\mathrm{r}(\mathrm{C} 5 \cdots \mathrm{C} 6)$ corresponding to the $\mathrm{C}-\mathrm{C}$ breaking bonds and basin populations $(\bar{N})$ computed for different points along the IRC path for thermal opening of 1 and 3 are presented in Tables $\mathbf{1}$ and $\mathbf{2}$, respectively. In Figs. (2 and $\mathbf{3}$ ) the fragment of the IRC curve for the thermal ring aperture of cyclobutene 1 and cyclohexa-1,3-diene 3 are depicted. Snapshots of the ELF basins for the stationary points involved on the thermal ring opening reactions of 1 and 3 are presented in Fig. (4). In addition, marked domains of the structural stability and the Lewis-like formula representing bonding in different steps on the IRC path - revealed by BET - are given.

The thermal opening of cyclobutene 1 and cyclohexa-1,3-diene 3 can be represented by chemical equations where the arrow symbol is replaced by much more informative catastrophe sequence (see Computational Details).

1-cyclobutene (1): 1-5- $\mathrm{C}^{\dagger} \mathrm{C}[\mathrm{F}]_{2}\left[\mathrm{C}^{\dagger}\right]_{2}-0$ : buta-1,3-diene (2)

cyclohexa-1,3-diene (3): $1-6-[\mathrm{C}]_{2} \mathrm{C}^{\dagger}[\mathrm{F}]_{2}\left[\mathrm{C}^{\dagger}\right]_{2} \mathrm{C}^{\dagger}-0$ : (Z)-hexa1,3,5-triene (4)

Only two types of catastrophes are observed, namely the fold and cusp. An annihilation of the non-bonding, monosynaptic basins $\mathrm{V}(\mathrm{C})$ is achieved by fold $(\mathrm{F})$ and breaking of the $\mathrm{C}-\mathrm{C}$ single bonds, "reduction" of the $\mathrm{C}=\mathrm{C}$ double bonds to $\mathrm{C}-\mathrm{C}$ single bonds and formation of $\mathrm{C}=\mathrm{C}$ double bonds by cusp $\left(\mathrm{C}\right.$ or $\left.\mathrm{C}^{\dagger}\right)$. The thermal opening of cyclobutene 1 consists of five steps and the reaction of cyclohexa-1,3-diene 3 exhibits six steps. In the reaction of 1 two pairs 


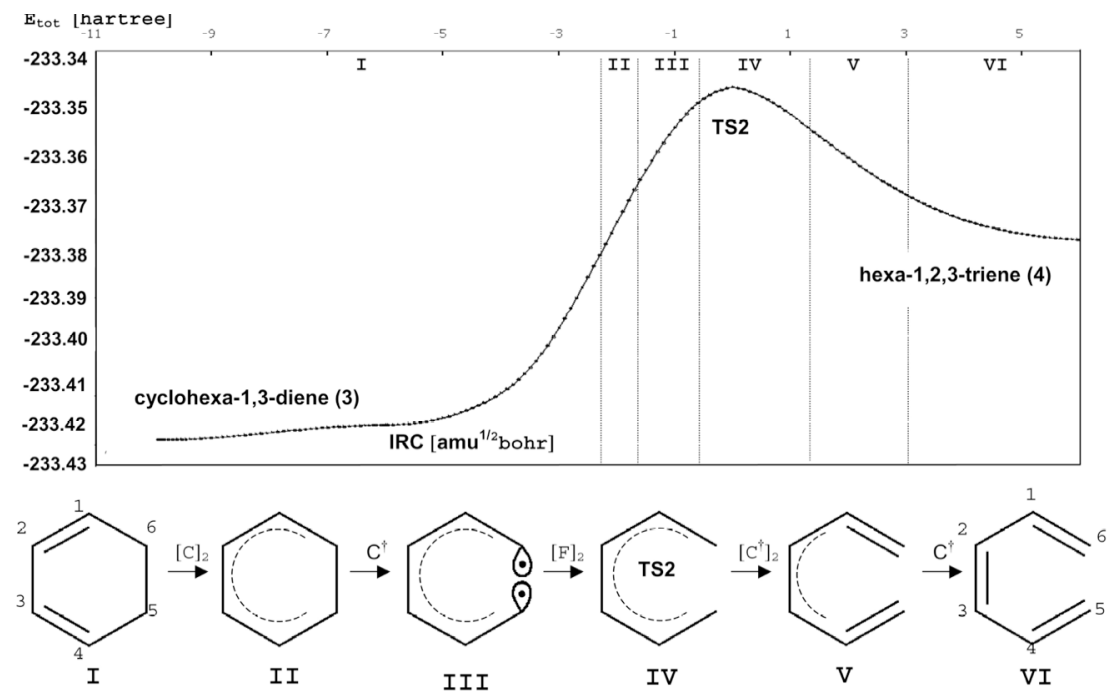

Fig. (3). Energy profiles for the the thermal ring aperture of cyclohexa-1,3-diene (3) calculated by means of the IRC method, with a step size of $0.1[\mathrm{amu} 1 / 2 \mathrm{bohr}]$. Below the graph a schematic representation of the reaction mechanism for each figure is depicted from the perspective of the ELF analysis (full lines and ellipses representing disynaptic and monosynaptic basins, respectively, dotted lines indicates a large basin population), the type of turning point is noted as in the text.

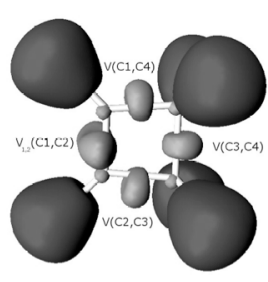

cyclobutene (1)

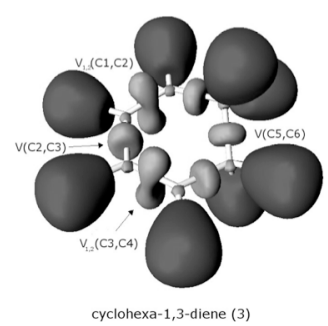

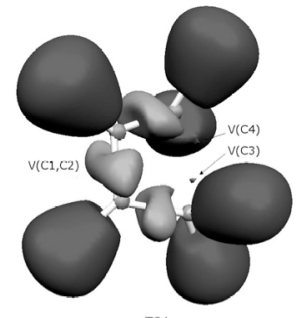

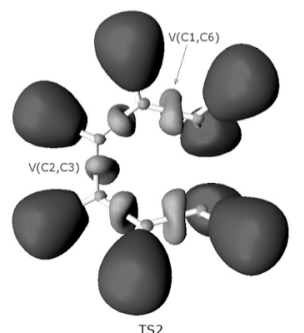

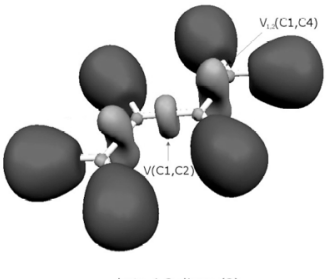

buta-1,2-diene (2)

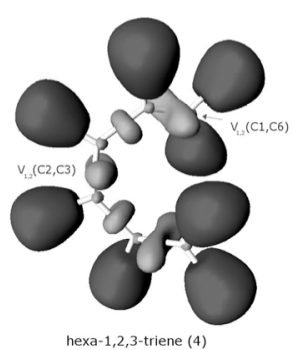

Fig. (4). Snapshots of the ELF basins for statiorary points of the cyclobutene and cyclohexane-1,3-diene ring opening reactions. Color legend: core, purple; monosynaptic, orange; disynaptic, green; hydrogenated, blue.

of catastrophes occur in the same point on the IRC path i.e. $[\mathrm{F}]_{2}$ between third and fourth step and $\left[\mathrm{C}^{\dagger}\right]_{2}$ between fourth and fifth step (Fig. 2). In the reaction of 3 there are three pairs of catastrophes occurring simultaneously i.e. $[\mathrm{C}]_{2}$ between first and second step, $[\mathrm{F}]_{2}$ between third and fourth step and $\left[\mathrm{C}^{\dagger}\right]_{2}$ between fourth and fifth step (Fig. 3). The observed pairs of catastrophes occur due to $\mathrm{C}_{2}$ symmetry which is retained during atomic rearrangement.

A main difference between the thermal opening of cyclobutene 1 and cyclohexa-1,3-diene 3 appears in the second step where in 1 as first is broken the $\mathrm{C} 3-\mathrm{C} 4$ single bond while in 3 the two $\mathrm{C} 1=\mathrm{C} 2$ and $\mathrm{C} 3=\mathrm{C} 4$ double bonds are "reduced" to the $\mathrm{C} 1-\mathrm{C} 2$ and $\mathrm{C} 3-\mathrm{C} 4$ single bonds. The opposite situation is observed in third step and in cyclobutene 1 the $\mathrm{C} 1=\mathrm{C} 2$ double bond is "reduced" to the $\mathrm{C} 1-\mathrm{C} 2$ single bond while in cyclohexa-1,3-diene 3 the C5-C6 single bond is broken. The fourth and fifth steps are similar in both reactions. The monosynaptic, non-bonding attractors/basins $\mathrm{V}(\mathrm{C})$, localised in a region of the C3-C4 (1) and C5-C6 (3) single bonds, are annihili- ted due to two fold catastrophes (IV step). The electron density is delocalized over whole carbon skeleton. In the fifth step the $\mathrm{C} 1=\mathrm{C} 4$ and $\mathrm{C} 2=\mathrm{C} 3$ double bonds in cyclobutene 1 and the $\mathrm{C} 1=\mathrm{C} 6$ and $\mathrm{C} 4=\mathrm{C} 5$ double bonds in cyclohexa-1,3-diene 3 are formed by two cusp catastrophes. The sixth step is observed only for the thermal opening of cyclohexa-1,3-diene 3 and yields a formation of the third $\mathrm{C} 2=\mathrm{C} 3$ double bond.

On the basis of the BET methodology both thermal opening reactions may be characterised as leading through distinguished phases: a) a "reduction" of the $\mathrm{C}=\mathrm{C}$ double bonds to single bonds, b) breaking of the $\mathrm{C}-\mathrm{C}$ single bond with the smallest basin population, and c) formation of new $\mathrm{C}=\mathrm{C}$ double bonds. As indicated by the catastrophe sequences an order of different steps may vary, however both reactions end with the cusp catastrophes i.e. $\left[\mathrm{C}^{\dagger}\right]_{2}$ in cyclobutene 1 and $\left[\mathrm{C}^{\dagger}\right]_{2} \mathrm{C}^{\dagger}$ in cyclohexa-1,3-diene 3 . They lead to a formation of the $\mathrm{C} 1=\mathrm{C} 4, \mathrm{C} 2=\mathrm{C} 3$ and the $\mathrm{C} 2=\mathrm{C} 3, \mathrm{C} 1=\mathrm{C} 6, \mathrm{C} 4=\mathrm{C} 5$ double bonds, respectively. 
Table 1. The Mean Electron Populations ( $\bar{N}$ in e) of the ELF-basins in Different Steps of the Thermal Opening of Cyclobutene (1) Studied at the B3LYP/6-31G(d) Computational Level. The C(C) Core Basins and Protonated V(C,H) Basins are not Presented. The Basin Populations Correspond to first Point Calculated after Respective Catastrophe

\begin{tabular}{|c|c|c|c|c|c|c|c|}
\hline $\begin{array}{l}\text { Step/Basin } \\
\text { r(C3 } \cdots 4)\end{array}$ & $\begin{array}{c}\text { I, Cyclobutene (1) } \\
1.575 \AA\end{array}$ & $\begin{array}{c}\text { II } \\
2.025 \AA\end{array}$ & $\begin{array}{c}\text { III } \\
2.115 \AA\end{array}$ & $\begin{array}{l}\text { III, TS4 } \\
2.143 \AA\end{array}$ & $\begin{array}{c}\text { IV } \\
2.187 \AA\end{array}$ & $\begin{array}{c}V^{1)} \\
2.426 \AA\end{array}$ & $\begin{array}{c}\mathrm{V}, \text { buta-1,3-diene (2) } \\
3.704 \AA\end{array}$ \\
\hline $\mathrm{V}_{1}(\mathrm{C} 1, \mathrm{C} 2)$ & 1.76 & 1.49 & \multirow[t]{2}{*}{\}$_{3.24}$} & \multirow[t]{2}{*}{\}$_{3.17}$} & \multirow[t]{2}{*}{\} 3.03} & \multirow[t]{2}{*}{\} 2.29} & \multirow[t]{2}{*}{\} 2.20} \\
\hline $\mathrm{V}_{2}(\mathrm{C} 1, \mathrm{C} 2)$ & 1.76 & 1.49 & & & & & \\
\hline $\mathrm{V}_{\mathrm{I}}(\mathrm{C} 2, \mathrm{C} 3)$ & \multirow[t]{2}{*}{\}$_{1.96}$} & \multirow[t]{2}{*}{\}$_{2.22}$} & \multirow[t]{2}{*}{\} 2.40} & \multirow[t]{2}{*}{\}$_{2.50}$} & \multirow[t]{2}{*}{\}$_{2.90}$} & 1.80 & 1.72 \\
\hline $\mathrm{V}_{2}(\mathrm{C} 2, \mathrm{C} 3)$ & & & & & & 1.52 & 1.72 \\
\hline $\mathrm{V}_{1}(\mathrm{Cl}, \mathrm{C} 4)$ & \multirow[t]{2}{*}{\}$_{1.96}$} & \multirow[t]{2}{*}{\}$_{2.22}$} & \multirow[t]{2}{*}{\}$_{2.40}$} & \multirow[t]{2}{*}{\}$_{2.50}$} & \multirow[t]{2}{*}{\} 2.90} & 1.80 & 1.72 \\
\hline $\mathrm{V}_{2}(\mathrm{C} 1, \mathrm{C} 4)$ & & & & & & 1.52 & 1.72 \\
\hline $\mathrm{V}(\mathrm{C} 3)$ & - & 0.58 & 0.44 & 0.36 & - & - & - \\
\hline $\mathrm{V}(\mathrm{C} 3, \mathrm{C} 4)$ & 1.77 & - & - & - & - & - & - \\
\hline $\mathrm{V}(\mathrm{C} 4)$ & - & 0.58 & 0.44 & 0.36 & - & - & - \\
\hline
\end{tabular}

1) The buta-1,3-diene 2 in the $s$-cis conformation.

${ }^{2)}$ The buta-1,3-diene $\mathbf{2}$ in the $s$-trans conformation, systematic name with numbering as in isolated molecule.

Table 2. The Mean Electron Populations ( $\bar{N}$ in e) of the ELF-basins in Different Steps of the Thermal Opening of cyclohexa-1,3-diene (3) Studied at the B3LYP/6-31G(d) Computational Level. The C(C) Core Basins and Protonated V(C,H) Basins are not Presented. The Basin Populations Correspond to First Point Calculated after Respective Catastrophe

\begin{tabular}{|c|c|c|c|c|c|c|c|}
\hline $\begin{array}{l}\text { Step/Basin } \\
\text { r(C5 }{ }^{\cdots} \text { C6) }\end{array}$ & $\begin{array}{c}\text { I, cyclohexa-1,3-diene (3) } \\
1.540 \AA\end{array}$ & $\begin{array}{c}\text { II } \\
1.974 \AA\end{array}$ & $\begin{array}{c}\text { III } \\
2.065 \AA\end{array}$ & $\begin{array}{l}\text { IV, TS6 } \\
2.281 \AA\end{array}$ & $\begin{array}{c}V \\
2.684 \AA\end{array}$ & $\begin{array}{c}V I \\
2.986 \AA\end{array}$ & $\begin{array}{c}\text { VI, hexa-1,3,5-triene (4) }{ }^{1)} \\
3.418 \AA\end{array}$ \\
\hline $\mathrm{V}_{1}(\mathrm{C} 1, \mathrm{C} 2)$ & 1.80 & \multirow{2}{*}{\}$_{3.37}$} & \multirow{2}{*}{\} 3.28} & \multirow{2}{*}{\} 2.81} & \multirow{2}{*}{\} 2.27} & \multirow{2}{*}{\} 2.18} & \multirow{2}{*}{\} 2.16} \\
\hline $\mathrm{V}_{2}(\mathrm{C} 1, \mathrm{C} 2)$ & 1.70 & & & & & & \\
\hline $\mathrm{V}_{1}(\mathrm{C} 2, \mathrm{C} 3)$ & \multirow{2}{*}{\} 2.16} & \multirow{2}{*}{\} 2.32} & \multirow{2}{*}{\} 2.41} & \multirow{2}{*}{32.88} & \multirow{2}{*}{\} 3.35} & 1.35 & 1.72 \\
\hline $\mathrm{V}_{2}(\mathrm{C} 2, \mathrm{C} 3)$ & & & & & & 2.09 & 1.76 \\
\hline $\mathrm{V}_{1}(\mathrm{C} 3, \mathrm{C} 4)$ & 1.78 & \multirow{2}{*}{\} 3.37} & \multirow{2}{*}{\} 3.28} & \multirow{2}{*}{32.81} & \multirow{2}{*}{\} 2.27} & \multirow{2}{*}{\} 2.19} & \multirow{2}{*}{\} 2.16} \\
\hline $\mathrm{V}_{2}(\mathrm{C} 3, \mathrm{C} 4)$ & 1.72 & & & & & & \\
\hline $\mathrm{V}_{1}(\mathrm{C} 4, \mathrm{C} 5)$ & \multirow{2}{*}{\} 1.97} & \multirow{2}{*}{\} 2.15} & \multirow{2}{*}{\} 2.25} & \multirow{2}{*}{33.08} & 1.93 & 1.84 & 1.80 \\
\hline $\mathrm{V}_{2}(\mathrm{C} 4, \mathrm{C} 5)$ & & & & & 1.47 & 1.61 & 1.67 \\
\hline $\mathrm{V}_{1}(\mathrm{C} 1, \mathrm{C} 6)$ & \multirow{2}{*}{\} 1.97} & \multirow{2}{*}{\}$_{2.16}$} & \multirow{2}{*}{\} 2.25} & \multirow{2}{*}{33.08} & 1.90 & 1.84 & 1.80 \\
\hline $\mathrm{V}_{2}(\mathrm{C} 1, \mathrm{C} 6)$ & & & & & 1.49 & 1.61 & 1.66 \\
\hline $\mathrm{V}(\mathrm{C} 5)$ & - & - & 0.64 & - & - & - & - \\
\hline $\mathrm{V}(\mathrm{C} 5, \mathrm{C} 6)$ & 1.85 & 1.43 & - & - & - & - & - \\
\hline $\mathrm{V}(\mathrm{C} 5)$ & - & - & 0.64 & - & - & - & - \\
\hline
\end{tabular}

${ }^{1)}$ The hexa-1,3,5-triene (4) systematic name with numbering as in isolated molecule.

A comparison of the IRC paths with marked domains of the structural stability (Fig. 2 and 3) reveals that TS1 is found in the third step for cyclobutene 1. It is characterized by two non-bonding monosynaptic basins $\mathrm{V}(\mathrm{C} 3), \mathrm{V}(\mathrm{C} 4)$ localized in regions of already broken $\mathrm{C} 3-\mathrm{C} 4$ bond. In case of cyclohexa-1,3-diene 3, the reaction can be considered as more progressed because TS2 is found in the fourth step where the non-bonding attractors $\mathrm{V}(\mathrm{C} 5)$ and $\mathrm{V}(\mathrm{C} 6)$ are already annihilated. The $\mathrm{C}-\mathrm{C}$ bonds are represented by single disynaptic basins $\mathrm{V}(\mathrm{C}, \mathrm{C})$ and the electron density is delocalized over carbon skeleton. It is worth emphasazing, that "new" double bonds are not formed in TS1 and TS2.

The BET allows monitoring the distances at which the $\mathrm{C} 3-\mathrm{C} 4$ single bond in cyclobutene 1 and the $\mathrm{C} 5-\mathrm{C} 6$ one in cyclohexa-1,3diene 3 are broken. It is about $2.03 \AA$ and $2.06 \AA$, respectively. A comparison of the basin populations computed for different points on the IRC path for cyclobutene 1 (Table 1) and cyclohexa-1,3diene 3 (Table 2) reveals a redistribution of the electron density. The electrons in cyclobutene 1 are redistributed from the $\mathrm{C} 1=\mathrm{C} 2$ double and $\mathrm{C} 3-\mathrm{C} 4$ single bonds to the $\mathrm{C} 1-\mathrm{C} 4$ and $\mathrm{C} 2-\mathrm{C} 3$ single bonds. A flux of electron density between basins is regular with exception of the $\mathrm{V}(\mathrm{C} 1, \mathrm{C} 2)$ basin which population in step III is larger than in step II. In cyclohexa-1,3-diene 3, the electron density is redistributed from the $\mathrm{C} 5-\mathrm{C} 6$ single bond and the two $\mathrm{C} 1-\mathrm{C} 2$ and C3-C4 double bonds to three $\mathrm{C} 2-\mathrm{C} 3, \mathrm{C} 1-\mathrm{C} 6$ and $\mathrm{C} 4-\mathrm{C} 5$ single bonds. The electron density redistribution between the valence basins is regular (Table 2).

A detailed analysis of the thermal opening of cyclobutene 1 reveals that in the first step a topology of the ELF function obtained 
for the reacting molecule is the same as observed in isolated case (Fig. 2). Cyclobutene 1 consists of two $\mathrm{C} 1-\mathrm{C} 4$ and $\mathrm{C} 2-\mathrm{C} 3$ single bonds described by single, bonding disynaptic basins $\mathrm{V}(\mathrm{Ci}, \mathrm{Cj})$ with $1.96 \mathrm{e}$, the $\mathrm{C} 1=\mathrm{C} 2$ double bond, characterised by two bonding disynaptic basins $\mathrm{V}_{\mathrm{i}=1,2}(\mathrm{C} 1, \mathrm{C} 2)$, with $1.76 \mathrm{e}(3.52 \mathrm{e})$ and the $\mathrm{C} 3-\mathrm{C} 4$ single bond described by single bonding basin $\mathrm{V}(\mathrm{C} 3, \mathrm{C} 4)$ with $1.77 \mathrm{e}$. It is worth emphasazing, that the $\mathrm{C} 3-\mathrm{C} 4$ single bond which undergoes homolytic breaking has essentially smaller population than other single bonds. All attractors localized for cyclobutene 1 and buta1,3-diene 3 are presented at Figs. ( 2 and 3). In this step the basin population of the $\mathrm{C} 3-\mathrm{C} 4$ bond decreases by 0.61 e and of the $\mathrm{C} 1=\mathrm{C} 2$ bond by $0.54 \mathrm{e}$ while the $\mathrm{C} 1-\mathrm{C} 4$ and $\mathrm{C} 2-\mathrm{C} 3$ bonds are saturated with the electron density by $0.26 \mathrm{e}$. It is worthy to mention that these points on the IRC, which can be related to homolitic C3-C4 breaking bond to afford the biradical system II, are located ca. 34 $\mathrm{kcal} / \mathrm{mol}(\mathrm{r}(\mathrm{C} 3 \cdots \mathrm{C} 4)=2.03 \AA)$ above cyclobutene 1 . In the second step the $\mathrm{C} 3-\mathrm{C} 4$ bond is broken and the cusp catastrophe $\left(\mathrm{C}^{\dagger}\right)$ leads to formation of two monosynaptic non-bonding attractors $\mathrm{V}(\mathrm{C} 3)$ and $\mathrm{V}(\mathrm{C} 4)$ with a basin population of $0.58 \mathrm{e}$ each one. In the third step which is very short (considering the number of points on the IRC path) and contains TS1 the $\mathrm{C} 1=\mathrm{C} 2$ double bond is "reduced" to C1-C2 single bond. The catastrophe is cusp (C) and only single disynaptic basin $\mathrm{V}(\mathrm{C} 1, \mathrm{C} 2)$ is observed. In comparison to step II the basin population of $\mathrm{V}(\mathrm{C} 1, \mathrm{C} 2)$ increases by $0.26 \mathrm{e}$. The redistribution of the electron density is not regular and the basin population of the C1-C2 in this step is larger (3.24e) than in step II (2.98e). In the fourth step two monosynaptic, non-bonding basins $\mathrm{V}(\mathrm{C} 3)$ and $\mathrm{V}(\mathrm{C} 4)$ dissapears due to two fold catastrophes take place simultaneously $[\mathrm{F}]_{2}$. The molecule is characterised by three bonding disynaptic basins $\mathrm{V}(\mathrm{Ci}, \mathrm{Cj})$ and delocalized electron density. From topological point of view the reaction is terminated in step $\mathrm{V}$ where two simultaneous cups catastrophes $\left[\mathrm{C}^{\dagger}\right]_{2}$ lead to formation of two $\mathrm{C} 2=\mathrm{C} 3$ and $\mathrm{C} 1=\mathrm{C} 4$ double bonds described by two pairs of the bonding, disynaptic basins $\mathrm{V}_{\mathrm{i}=1,2}(\mathrm{C} 2, \mathrm{C} 3)$ and $\mathrm{V}_{\mathrm{i}=1,2}(\mathrm{C} 1, \mathrm{C} 4)$ with populations 1.80 and $1.52 \mathrm{e}$. The electron redistribution is not finished until the geometrical structure obtains energetic minimum (buta-1,3-diene 2) where both bonds have the basin population equal $1.72 \mathrm{e}$.

The thermal opening of cyclohexa-1,3-diene 3 begins in the first step where topology of the ELF function is the same as in isolated molecule (Fig. 3). The C2-C3 bond, formally of the single type, has the basin population slightly larger than $2 \mathrm{e}(2.16 \mathrm{e})$ while other C1-C6, C4-C5 and C5-C6 single bonds exhibit the basin population smaller than $2 \mathrm{e}(1.97,1.85 \mathrm{e})$. It is worth emphasazing that similarly as observed for cyclobutene 1 the smallest basin population $(1.85 \mathrm{e})$ is found for the C5-C6 bond, which undergoes homolytic breaking. The second step is determined by two cusp catastrophes occurring simultaneously $[\mathrm{C}]_{2}$ for the $\mathrm{C} 5$ \% $\mathrm{C} 6$ separation equal about $1.97 \AA$. The $\mathrm{C} 1=\mathrm{C} 2$ and $\mathrm{C} 3=\mathrm{C} 4$ double bonds are reduced to the $\mathrm{C} 1-\mathrm{C} 2$ and $\mathrm{C} 3-\mathrm{C} 4$ single bonds. The most important event on the IRC path occurs in the third step where the C5-C6 single bond is broken. In the cusp catastrophe $\left(\mathrm{C}^{\dagger}\right)$ the disynaptic bonding basin $\mathrm{V}(\mathrm{C} 5, \mathrm{C} 6)$ is "split" into two non-bonding disynaptic basins $\mathrm{V}(\mathrm{C} 5)$, $\mathrm{V}(\mathrm{C} 6)$ with a basin population of $0.64 \mathrm{e}$ each one. It is worthy to mention that these points on the IRC, which can be related to homolitic C5-C6 breaking bond to afford the biradical system III, are located ca. $40 \mathrm{kcal} / \mathrm{mol}(\mathrm{r}(\mathrm{C} 5 \cdots \mathrm{C} 6)=2.06 \AA)$ above cyclohexa-1,3diene 3 . The fourth step begins with two fold catastrophes $[\mathrm{F}]_{2}$ which lead to annihilation of the non-bonding, monosynaptic attractors $\mathrm{V}(\mathrm{C} 5), \mathrm{V}(\mathrm{C} 6)$. The catastrophes are observed at about $2.28 \AA$ and the molecule exhibits delocalized electron density over the carbon skeleton. This topology of the ELF function characterizes TS2. In the fifth step two pairs of cusp catastrophes found at about $2.68 \AA$ lead to a formation of the $\mathrm{C} 4=\mathrm{C} 5$ and $\mathrm{C} 1=\mathrm{C} 6$ double bonds with pairs of the bonding, disynaptic basins $\mathrm{V}_{\mathrm{i}=1,2}(\mathrm{C} 4, \mathrm{C} 5)$ and $\mathrm{V}_{\mathrm{i}=1,2}(\mathrm{C} 1, \mathrm{C} 6)$. The reaction is terminated in step VI where the last double bond $\mathrm{C} 2=\mathrm{C} 3$ is created. An analysis of the basin populations in hexa-1,3,5-triene 3 (Table 2) shows that during the reaction course the $\mathrm{C} 1-\mathrm{C} 2$ and $\mathrm{C} 3-\mathrm{C} 4$ single bonds have been depopulated by $1.34 \mathrm{e}$ and the $\mathrm{C} 2=\mathrm{C} 3$ double bond has been saturated by $1.32 \mathrm{e}$. Similarly, the $\mathrm{C} 1=\mathrm{C} 6$ and $\mathrm{C} 4=\mathrm{C} 5$ double bonds $(3.47 \mathrm{e})$ have been saturated by $1.5 \mathrm{e}$.

The evolution of the bonding along the reaction path provides also shed lights onto the conrotatory and disrotatory character of the thermal ring opening mechanism of cyclobutene 1 and cyclohexa1,3-diene 3 respectively. In the case of 1 , the reduction of the $\mathrm{C} 1$ $\mathrm{C} 2$ double bond to a single bond significantly lowers the rotation barrier around this bond. The rotation around $\mathrm{C} 1-\mathrm{C} 2$ is therefore the most easily accessible deformation enabling the system to evolves towards the buta-1,3-diene 2 equilibrium geometry [78]; this motion which conserves the $\mathrm{C} 2$ symmetry is therefore conrotatory. In cyclohexa-1,3-diene 3, the C2-C3 single bond becomes double which hampers the free rotation around the $\mathrm{C} 2-\mathrm{C} 3$ moiety, while almost free rotation becomes possible around $\mathrm{C} 1-\mathrm{C} 2$ and $\mathrm{C} 3-\mathrm{C} 4$; conservation of the Cs symmetry (the sigma plane is conserved) implies a disrotatory mechanism.

\section{CONCLUSIONS AND PERPECTIVES}

A chemical reaction involves breaking of bonds between atoms and the formation of new ones; then, it occurs when atoms in a molecule change their specific arrangement and the time scale of chemistry is therefore the time scale for the motion of atoms. In this respect, the analyses of reaction pathways must take into account the passage of time. The way in which chemical bonds are broken/forming along the progress of a chemical reaction are imagined and subsequently represented in drawings or models is a fundamental part of the chemist's activity. In general, such structural elucidation of species along the corresponding reaction mechanism is a difficult but illuminating process, motivated by a desire to enhance the basic understanding of chemical reactivity.

Throughout this study we have been able to assess the utility of the combination of the electron localization function (ELF) and Thom's catrastophe teory (CT) as a poweful tool to analyze the course a given chemical rearrangement. The progress of the reaction is monitorized by the changes of the ELF structural stability domains (SSD), each being change controlled by a turning point (TP) derived from CT. The identification of the TPs connecting the ELF-SSDs along the reaction pathway allows a rigorous characterization of the sequence of electron pair rearrangements taking place during a chemical transformation, such as multiple bond forming/breaking processes, ring closure processes, creation/annihilation of lone pairs, transformations of C-C multiple bonds into single ones, and otrher electronic rearrangements. As a working model, we consider the thermal ring aperture of cyclobutene and cyclohexa-1,3-diene.

This procedure allows us to search for the degree of fitness of the Lewis hypothesis of chemical bonding as an electron pairing phenomena. This goal has required extension of the relationships between the traditional chemical concepts and the quantum mechanical ones. It is in agreement with physical laws and quantum theoretical insights, and it can be considered as an appropriate tool to 
tackle chemical reactivity with a wide range of possible applications, and the universal behavior that it predicts.

\section{ACKNOWLEDGMENTS}

This work was supported by the Ministerio de Educación y Ciencia (MEC) projects (CTQ2006-15447-C02-01 and CTQ200914541-C02-01), Universitat Jaume I-Fundación Bancaixa (project $\mathrm{n}^{\circ}$ P1.1B2007-25), and PROMETEO program (PROMETEO/2009/053) of the Generalitat Valenciana. L.R.D. acknowledges research funds provided by the Ministerio de Ciencia e Innovación of the Spanish Government (project CTQ2009-11027/BQU). The authors are also grateful to the Servei d'Informatica, Universitat Jaume I.

\section{REFERENCES}

[1] Bernstein, R. B.; Zewail, A. H. Real-Time Laser Femtochemistry: Viewing the Transition States from Reagents to Products. Chem. Eng. News, 1998, 66, 24 .

[2] Zewail, A. H. Femtochemistry: Atomic-Scale Dynamics of the Chemical Bond. J. Phys. Chem. A, 2000, 104, 5660.

[3] Berry, R. S.; Rice, S. A.; Ross, J. Physical Chemistry, 2nd ed.; Oxford University Press: Oxford, U.K., 2000.

[4] Breslow, R. Determining the Geometries of Transition States by Use of Antihydrophobic Additives in Water. Acc. Chem. Res., 2004, 37, 471.

[5] Gessner, O., Lee, A. M. D., Shaffer, J. P., Reister, H., Levchenko, S. V., Krylov, A. I., Underwood, J. G., Shi, H., East, A. L. L., Wardlaw, D. M., Femtosecond Multidimensional Imaging of a Molecular Dissociation. Science, 2006, 311, 219.

[6] Woutersen, S.; Bakker, H. J. Resonant intermolecular transfer of vibrational energy in liquid water. Nature, 1999, 402, 507.

[7] Hurley, S. M.; Dermota, T.E.; Hydutsky, D.P.; Castleman, A.W. Dynamics of Hydrogen Bromide Dissolution in the Ground and Excited States. Science, 2002, 298, 202 .

[8] Truong, T.V.; Xu, L.; Shen, Y. R. Early Dynamics of Guest-Host Interaction in Dye-Doped Liquid Crystalline Materials. Phys. Rev. Lett., 2003, 90, 193902.

[9] Ihee, H.; Lobastov, V.A.; Gomez, U.M.; Goodson, B.M.; Srinivasan, R.; Ruan, C.Y.; Zewail, A.H., Direct Imaging of Transient Molecular Structures with Ultrafast Diffraction. Science, 2001, 291, 458.

[10] Lindenberg, A.M.; Larsson, J.; Sokolowski-Tinten, K.; Gaffney, K.J.; Blome, C.; Synnergren, O.; Sheppard, J.; Caleman, C.; MacPhee, A.G.; Weinstein, D.; Lowney, D.P.; Allison, T.K.M.; Matthews, T.; Falcone, R.W.; Cavalieri, A.L.; Fritz, D.M.; Lee, S.H.; Bucksbaum, P.H.; Reis, D.A.; Rudati, J.; Fuoss, P.H.; Kao, C.C.; Siddons, D.P.; Pahl, R.; Als-Nielsen, J.; Duesterer, S.; Ischebeck, R.; Schlarb, H.; Schulte-Schrepping, H.; Tschentscher, T.; Schneider, J.; von der Linde, D.; Hignette, O.; Sette, F.; Chapman, H.N.; Lee, R.W.; Hansen, T.N.; Techert, S.; Wark, J.S.; Bergh, M.; Huldt, G.; van der Spoel, D.; Timneanu, N.; Hajdu, J.; Akre, R.A.; Bong, E.; Krejcik, P.; Arthur. J.; Brennan, S.; Luening. K.; Hastings, J.B. Atomic-Scale Visualization of Inertial Dynamics. Science, 2005, 308, 392.

[11] Drescher, M.; Hentschel, M.; Kienberger, R.; Tempea. G.; Spielmann, C.; Reider, G.A.; Corkum, P.B.; Krausz, F. X-ray Pulses Approaching the Attosecond Frontier. Science, 2001, 291, 1923.

[12] Paul, P.M.; Toma, E.S.; Breger, P.; Mullot, G.; Auge, F.; Balcou, P.; Muller, H.G.; Agostini, P. Observation of a Train of Attosecond Pulses from High Harmonic Generation, Science, 2001, 292, 1689.

[13] Hentschel, M.; Kienberger, R.; Spielmann, C.; Reider, G.A.; Milosevic, N.; Brabec, T.; Corkum, P.; Heinzmann, U.; Drescher, M.; Krausz, F., Attosecond metrology, Nature, 2001, 414, 509.

[14] Sutcliffe, B. T. The idea of a potential energy surface. Molecular Physics, 2006, 104, 715.

[15] Fukui, K. Formulation of the reaction coordinate. J. Phys. Chem., 1970, 74, 4161.

[16] Hoffman, R.; Shaik, S.; Hiberty, P. C. A Conversation on VB vs MO Theory: A Never-Ending Rivalry? Acc. Chem. Res., 2003, 36, 750.

[17] Truhlar, D. G, Molecular Modeling of Complex Chemical Systems. J. Am. Chem. Soc., 2008, 130, 16824.

[18] Fukui, K. The path of chemical reactions - the IRC approach. Acc. Chem. Res., 1981, 14, 363.

[19] Shaik, S.; Ioffe, A.; Reddy, A. C.; Pross, A. Is the avoided crossing state a good approximation for the transition state of a chemical reaction? An analysis of Menschutkin and ionic SN2 reactions. J. Am. Chem. Soc., 1994, 116, 262.

[20] Eyring, H. The Activated Complex in Chemical Reactions. J. Chem. Phys. 1935, 3, 107. Wigner, E. The transition state method. Trans. Faraday Soc., 1938, 34, 29.
[21] Hammond, G. S. A Correlation of Reaction Rates. J. Am. Chem. Soc., 1955, 77,334 .

[22] Leffler, J. E. Parameters for the Description of Transition States. Science, 1953, 117, 340 .

[23] Shi, Z.; Boyd, R. J. Charge development at the transition state: a secondorder Moeller-Plesset perturbation study of gas-phase SN2 reactions. J. Am. Chem. Soc., 1991, 113, 1072.

[24] Bader, R. F. W.; MacDougall, P. J. Toward a theory of chemical reactivity based on the charge density. J. Am. Chem. Soc., 1985, 107, 6788.

[25] Balakrishnan, N.; Sathyamurthy, N. Maximization of entropy during a chemical reaction. Chem. Phys. Letters, 1989, 164, 267.

[26] Ho, M.; Schmider, H. L.; Weaver, D. F.; Smith, V. H., Jr.; Sagar, R. P.; Esquivel, R. O. Shannon entropy of chemical changes: $S N 2$ displacement reactions. Int. J. Quantum Chem., 2000, 77, 376.

[27] Knoerr, E. H.; Eberhart, M. E. Toward a Density-Based Representation of Reactivity: SN2 Reaction. J. Phys. Chem. A, 2001, 105, 880.

[28] Tachibana, A. Electronic energy density in chemical reaction systems. $J$. Chem. Phys., 2001, 115, 3497.

[29] Mulliken, R. Electronic Population Analysis on LCAO-MO Molecular Wave Functions. I. J. Chem. Phys., 1955, 23, 1833.

[30] Löwdin, P. O. On the Non-Orthogonality Problem Connected with the Use of Atomic Wave Functions in the Theory of Molecules and Crystals. J. Chem. Phys., 1950, 18, 365.

[31] Reed, A. E.; Curtiss, L. A.; Weinhold, F. Intermolecular interactions from a natural bond orbital, donor-acceptor viewpoint. Chem. Rev., 1988, 88, 899.

[32] Bader, R. F. W. Atoms In molecules. A Quantum Theory, Clarendron Press, Oxford, 1990.

[33] Grimme S.; Muck-Lichtenfeld C.; Erker G.; Kehr G.; Wang H.D.; Beckers H.; Willner H.; When Do Interacting Atoms Form a Chemical Bond? Spectroscopic Measurements and Theoretical Analyses of Dideuteriophenanthrene. Angew. Chem. Int. Ed., 2009, 48, 2592.

[34] Becke, A. D., Edgecombe, K. E. A simple measure of electron localization in atomic and molecular systems. J. Chem. Phys., 1990, 92, 5397.

[35] Savin, A.; Jepsen, O.; Flad, J.; Andersen, O.K.; Preuss, H.; von Schnering, H.G. Electron Localization in Solid-State Structures of the Elements: the Diamond Structure. Angew. Chem. Int. Ed. Engl., 1992, 31, 187.

[36] Krokidis, X.; Vuilleumier, R.; Borgis, D.; Silvi, B. A topological analysis of the proton transfer in $\mathrm{H}_{5} \mathrm{O}_{2}{ }^{+}$. Mol. Phys., 1999, 96, 265.

[37] Krokidis, X.; Noury, S.; Silvi, B. Characterization of Elementary Chemical Processes by Catastrophe Theory. J. Phys. Chem. A, 1997,101, 7277.

[38] Li, X. Y.; Zeng, Y. L.; Meng, L. P.; Zheng, S. J. Topological Characterization of $\mathrm{HXO}(\mathrm{X}=\mathrm{Cl}, \mathrm{Br}, \mathrm{I})$ Isomerization. J. Phys. Chem. A, 2007, 111, 1530 .

[39] Li, X. Y.; Fan, H. M.; Meng, L. P.; Zeng, Y. L.; Zheng, S. J. Theoretical Investigation on Stability and Isomerizations of $\mathrm{CH}$ SO Isomers. J. Phys. Chem. A, 2007, 111, 2343.

[40] Zeng, Y. L.; Zheng, S. J.; Meng, L. P. Studies on Reactions INCX $\rightarrow$ IXCN $(\mathrm{X}=\mathrm{O}, \mathrm{S}$, and Se). Inorg. Chem., 2004, 43, 5311 .

[41] Zeng, Y. L.; Zheng, S. J.; Meng, L. P. AIM Studies on Reactions FNCX $\rightarrow$ FXCN (X = O, S, and Se). J. Phys. Chem. A, 2004, 108, 10527.

[42] Zeng, Y. L.; Meng, L. P.; Zheng, S. Studies on the reactions BrNCX $\rightarrow$ BrXCN (X=O, S, Se). J. Mol. Struct., 2004, 684, 103. Macchi, P.; Sironi, A. Chemical bonding in transition metal carbonyl clusters: complementary analysis of theoretical and experimental electron densities. Coord. Chem. Rev., 2003, 238, 383.

[43] Malcolm, N. O. J.; Popelier, P. L. A. On the Full Topology of the Laplacian of the Electron Density II: Umbrella Inversion of the Ammonia Molecule. $J$. Phys. Chem. A, 2001, 105, 7638.

[44] Polo, V.; Andrés, J.; Castillo, R.; Berski, S.; Silvi, B. Understanding the Molecular Mechanism of the 1,3-Dipolar Cycloaddition between Fulminic Acid and Acetylene in Terms of the Electron Localization Function and Catastrophe Theory. Chem.-Eur. J., 2004, 10, 5165.

[45] Berski, S.; Andrés, J.; Silvi, B.; Domingo, L. R. New Findings on the DielsAlder Reactions. An Analysis Based on the Bonding Evolution Theory. $J$. Phys. Chem. A, 2006, 110, 13939.

[46] Berski, S.; Andrés, J.; Silvi, B.; Domingo, L. R. The Joint Use of Catastrophe Theory and Electron Localization Function to Characterize Molecular Mechanisms. A Density Functional Study of the Diels-Alder Reaction between Ethylene and 1,3-Butadiene. J. Phys. Chem. A, 2003, 107, 6014.

[47] Andrés, J.; Berski, S.; Feliz, M.; Llusar, R.; Sensato, F.; Silvi, B. The nature of the chemical bond in di- and polynuclear metal cluster complexes as depicted by the analysis of the electron localization function. C. R. Chim., 2005, 8,1400 .

[48] Polo, V.; Andrés, J.; Silvi, B.; Berski, S.; Domingo, L. R. Understanding Reaction Mechanisms in Organic Chemistry from Catastrophe Theory Applied to the Electron Localization Function Topology. J. Phys. Chem., 2008, $112,7128$.

[49] Balanarayan, P.; Kavathekar, R.; Gadre, S. R. Electrostatic Potential Topography for Exploring Electronic Reorganizations in 1,3 Dipolar Cycloadditions. J. Phys. Chem. A, 2007, 111, 2733.

[50] Silvi, B., Savin, A., Classification of chemical bonds based on topological analysis of electron localization functions. Nature, 1994, 371, 683.

[51] Lewis G.N. The atom and the molecule. J.Amer.Chem.Soc., 1916, 38, 762. 
[52] Lewis, G. N. Valence and the Nature of the Chemical Bond. Chemical Catalog Company. 1926

[53] Thom, R., Stabilité Structurelle et Morphogénèse; Intereditions, Paris, 1972.

[54] Silvi, B. The synaptic order: a key concept to understand multicenter bonding. J. Mol. Struct., 2002, 614, 3 .

[55] Silvi, B. How topological partitions of the electron distributions reveal delocalization. Phys. Chem. Chem. Phys., 2004, 6, 256.

[56] Tielens, F.; Gracia, L.; Polo, V.; Andrés, J. A Theoretical Study on the Electronic Structure of Au-XO ${ }^{(0,-1,+1)}(\mathrm{X}=\mathrm{C}, \mathrm{N}$, and $\mathrm{O})$ Complexes: Effect of an External Electric Field. J. Phys. Chem. A, 2007, 111, 13255.

[57] Thom, R. Structural Stability and Morphogenesis: An Outline of a General Theory of Models Reading, 1975.

[58] Berski, S.; Latajka, Z. Quantum chemical topology description of the hydrogen transfer between the ethynyl radical and ammonia $\left(\mathrm{C}_{2} \mathrm{H}+\mathrm{NH}_{3}\right)-$ The electron localization function study. Chem. Phys. Lett., 2006, 426, 273.

[59] Krokidis, X.; Silvi, B.; Alikhani, M. E. Topological characterization of the isomerization mechanisms in $\mathrm{XNO}(\mathrm{X}=\mathrm{H}, \mathrm{Cl})$. Chem. Phys. Lett., 1998, 292, 35 .

[60] Krokidis, X.; Silvi, B.; Dezarnaud-Dandine, C.; Sevin, A. Topological study, using a coupled ELF and catastrophe theory technique, of electron transfer in the $\mathrm{Li}+\mathrm{Cl}_{2}$ system. New. J. Chem., 1988, 22, 1341.

[61] Michelini, M. D.; Sicilia, E.; Russo, N.; Alikhani, M. E.; Silvi, B. Topological Analysis of the Reaction of $\mathrm{Mn}^{+}\left({ }^{7} \mathrm{~S},{ }^{5} \mathrm{~S}\right)$ with $\mathrm{H}_{2} \mathrm{O}, \mathrm{NH}_{3}$, and $\mathrm{CH}_{4}$ Molecules. J. Phys. Chem. A, 2003, 107, 4862.

[62] Michelini, M. D.; Russo, N.; Alikhani, M. E.; Silvi, B. Energetic and topological analysis of the reaction of $\mathrm{Mo}$ and $\mathrm{Mo}_{2}$ with $\mathrm{NH}_{3}, \mathrm{C}_{2} \mathrm{H}_{2}$, and $\mathrm{C}_{2} \mathrm{H}_{4}$ molecules. J. Comput. Chem., 2005, 25, 1647.

[63] Michelini, M. D.; Russo, N.; Alikhani, M. E.; Silvi, B. Energetic and topological analyses of the oxidation reaction between $\operatorname{Mon}(n=1,2)$ and $\mathrm{N}_{2} \mathrm{O} . J$. Comput. Chem., 2005, 26, 1284.

[64] Santos, J. C.; Andrés, J.; Aizman, A.; Fuentealba, P.; Polo, V. A Theoretical Study on the Reaction Mechanism for the Bergman Cyclization from the Perspective of the Electron Localization Function and Catastrophe Theory. $J$. Phys. Chem. A, 2005, 109, 3687.

[65] Santos, J. C.; Polo, V.; Andrés, J. An electron localization function study of the trimerization of acetylene: Reaction mechanism and development of aromaticity. Chem. Phys. Lett., 2005, 406, 393.

[66] Polo, V.; Andrés, J. A joint study based on the electron localization function and catastrophe theory of the chameleonic and centauric models for the Cope rearrangement of 1,5-hexadiene and its cyano derivatives. J. Comput. Chem., 2005, 26, 1427.

[67] Polo, V.; Andrés, J. Lewis Acid and Substituent Effects on the Molecular Mechanism for the Nazarov Reaction of Penta-1,4-dien-3-one and Derivatives. A Topological Analysis Based on the Combined Use of Electron Locali- zation Function and Catastrophe Theory. J. Chem. Theor. Comput., 2007, 3, 816.

[68] Polo, V.; Gonzalez-Navarrete, P.; Andres, J.; Silvi, B. An electron localization function and catastrophe theory analysis on the molecular mechanism of gas-phase identity SN2 reactions. Theor. Chem. Acc., 2008, 120, 341.

[69] Becke, A. D. Density-functional thermochemistry. III. The role of exact exchange. J. Chem. Phys., 1993, 98, 5648.

[70] Lee, C.; Yang, W.; Parr, R. G. Development of the Colle-Salvetti correlationenergy formula into a functional of the electron density. Phys. Rev. B, 1988, 37,785 .

[71] Hehre, W. J.; Radom, L.; Schleyer, P. v. R.; Pople, J. A. Ab initio Molecular Orbital Theory; Wiley: New York, 1986.

[72] Schlegel, H. B. "Geometry Optimization on Potential Energy Surface," in Modern Electronic Structure Theory.; Ed. Yarkony D.R.: Singapore, 1994.

[73] González, C.; Schlegel, H. B. Reaction path following in mass-weighted internal coordinates. J. Phys. Chem., 1990, 94, 5523

[74] González, C.; Schlegel, H. B. Improved algorithms for reaction path following: Higher-order implicit algorithms. J. Chem. Phys., 1991, 95, 5853.

[75] Frisch, M. J.; Trucks, G. W.; Schlegel, H. B.; Scuseria, G. E.; Robb, M. A.; Cheeseman, J. R.; Montgomery, J., J. A. ; Vreven, T.; Kudin, K. N.; Burant, J. C.; Millam, J. M.; Iyengar, S. S.; Tomasi, J.; Barone, V.; Mennucci, B.; Cossi, M.; Scalmani, G.; Rega, N.; Petersson, G. A.; Nakatsuji, H.; Hada, M.; Ehara, M.; Toyota, K.; Fukuda, R.; Hasegawa, J.; Ishida, M.; Nakajima, T; Honda, Y; Kitao, O.; Nakai, H. Klene, M. Li, X; Knox, J. E; Hratchian, H. P.; Cross, J. B.; Adamo, C.; Jaramillo, J.; Gomperts, R.; Stratmann, R. E.; Yazyev, O.; Austin, A. J.; Cammi, R.; Pomelli, C.; Ochterski, J. W.; Ayala, P. Y.; Morokuma, K.; Voth, G. A.; Salvador, P.; Dannenberg, J. J.; Zakrzewski, V. G.; Dapprich, S.; Daniels, A. D.; Strain, M. C.; Farkas, O.; Malick, D. K.; Rabuck, A. D.; Raghavachari, K.; Foresman, J. B.; Ortiz, J. V.; Cui, Q.; Baboul, A. G.; Clifford, S.; Cioslowski, J.; Stefanov, B. B.; Liu, G.; Liashenko, A.; Piskorz, P.; Komaromi, I.; Martin, R. L.; Fox, D. J.; Keith, T.; Al-Laham, M. A.; Peng, C. Y.; Nanayakkara, A.; Challacombe, M.; Gill, P. M. W.; Johnson, B.; Chen, W.; Wong, M. W.; Gonzalez, C.; Pople, J. A Gaussian 03, Revision C.02, Gaussian, Inc., Wallingford CT, 2004

[76] Malcolm, O. J.; Popelier, P. L. A. The full topology of the Laplacian of the electron density: scrutinising a physical basis for the VSEPR model. Faraday Discuss, 2003, 124, 353.

[77] Popelier, P. in "Intermolecular Forces and Clusters", Ed. D.J.Wales, Structure and Bonding, Springer-Verlag, 2005, 115, 1.

[78] Chattaraj, P. K.; Fuentealba, P.; Gomez, B.; Contreras, R. WoodwardHoffmann Rule in the Light of the Principles of Maximum Hardness and Minimum Polarizability: DFT and Ab Initio SCF Studies. J. Am. Chem. Soc., 2000, $122,348$. 